THURSDAY, SEPTEMBER 8, I870

\section{THE MEDICAL SCHOOLS OF ENGLAND AND GERMANY*}

II.

$\mathrm{T}$

HE German University System, described in our last article, has been recently extended to other parts of the Continent. In Holland, for example, the progress made in this direction of late years has been immense, considering the small extent of the country. Again, in France, at the time that Duruy was Minister of Public Instruction, a measure was adopted which was prompted by the same tendency. One of the most distinguished sarsants of that country (Prof. Wurtz) was sent into Germany to collect information as to the great institutions which exist in that country for the promotion of natural science. The results of this inquiry are embodied in a voluminous report, illustrated with plans of the most important buildings. The favourable impression made on the mind of M. Wurtz by all that he saw in this journey may be judged of by the terms employed in the final paragraphs, in which he sums up his conclusions, and enforces the necessity of introducing German organisation into France.

If we pass from the consideration of the resources of English schools to the functions they perform and the ends they have in view, the contrast between Germany and England becomes still more striking. All German professors are State officials, and hold their posts, with rare exceptions, for life. Consequently, the special work which they have to perform in virtue of their calling is the purpose to which they have voluntarily devoted their existence. In Germany a young man who makes up his mind to a scientific career, dedicates himself from the first to the particular branch of science which he intends to follow, and remains true to it to the end. In this way he acquires a mastery over his speciality which could not be attained in any other way; and if he is a man of mark, he becomes the centre of what in Germany is called a "School," that is to say, he acquires a following of younger men to whom he communicates the precious fruits of his own work ; partly orally ; partly by demonstration, in such a way that the pupils learn from him in a short time, and in the most advantageous manner, what it would take years to acquire by self-instruction. In England, on the other hand, with the exception of the few scientific men who have studied in Germany, all are what we call "Autodidacten"-i.e. self-taught men, who have acquired their knowledge in spite of the want of opportunities. For there are very few investigators by profession, and, in the sense above referred to, no "Schools." The number of those who hold University Professorships is extremely small, and among these even there are few who, in the absence of independent means, are willing to devote themselves exclusively to a pursuit which brings in nothing.

Those who belong to that section of the community which is most fruitful in workers-those, namely, who are without the advantages either of birth or means-cannot, for want of substance, devote their lives to physiological research with that completeness which is necessary if great results are to be obtained. The most that they can do is to give their early ycars to investigation, with the understood intention of eventually abandoning natural science for those practical duties which are to be the occupation of their mature life, as well as the substantial reward of their previous labours. For the development of science great part of their work is lost, partly because there are no laboratories for instruction, but still more because their time becomes absorbed in other occupations at the very period at which it could be most advantageously devoted to this purpose.

It must, however, be borne in mind that, in Austria at all events, it was not zeal for science that induced the Government to take charge of its interests. The motive is rather to be looked for in the tendency which then existed to keep everything under the management of the central authority, and to maintain its control over all social relations. It is, however, of little consequence how the system originated; for a tree that bears good fruit is none the worse for the foulness which lies about its roots. Some may be inclined to doubt wh ther it is after all advantageous that the sciences should be represented in the Government. It will not be difficult to answer the question. The man who is occupied exclusively in research (and it is only such workers that science really cares for) is very slow in reaping the fruits of his labours. The results which are to be attained in the laboratory, however valuable they may be as materials for the future enrichment and development of the people, are not marketable. A single truth may afford work for a decennium, and often only begins to be productive after the death of its originator. The position of the philosopher is special. No one is more helpless and more completely dependent on the support of the public. With the artist, who stands in a closer relation to the man of science than any one else, it is far otherwise; for the wealthy patrons, whose houses he ornaments with his works, even if they are not always capable of appreciating them, are willing to pay him for them liberally. But in the case of the philosopher, it often happens that the work of many years may be compressed into a few pages.

A nation so well-to-do as the English might perhaps be expected to afford the means for the support of science independently of the Guverriment, especially now that the value of scientific culture is better understood than formerly. But even if the means were forthcoming, there would be no guarantee for their efficient distribution, unless that distribution were pluccl under the control of competent and responsible person; capable of justly estimating the future worth of a sciantinc worker from the earliest products of his mind. For this forecasting, endowments are necessary which are not to be met with every where and at all times. It is a great gain to any country to possess men fit to be entrusted with this responsibility; but, in order that they may be really useful, it is absolutely necessary for them to be in immediate relation with the central Government.

I have so far entered only into the general features of higher scientific education, without making any very special reference to medical studies. For the purpose of taking a more detailed view of the subject, we must examine more particularly the mutual relations of hospital and school. This will form the subject of a subsequent paper. S. STRICKER 